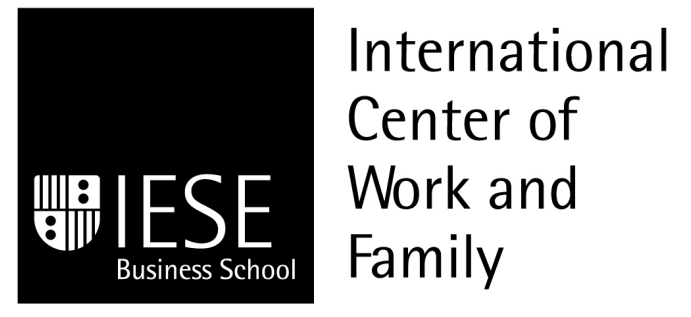

Working Paper

WP no 632

May, 2006

University of Navarra

\title{
CAREER INHIBITORS AND CAREER ENABLERS FOR EXECUTIVE WOMEN
}

\author{
Nuria Chinchilla \\ Consuelo León \\ Elizabeth Torres
}

Miguel Angel Canela 


\title{
CAREER INHIBITORS AND CAREER ENABLERS FOR EXECUTIVE WOMEN
}

\author{
Nuria Chinchilla* \\ Consuelo León** \\ Elizabeth Torres*** \\ Miguel Angel Canela***
}

\section{Abstract}

This paper is intended to contribute to the study of career inhibitors and career enablers for women. The analysis is based on data obtained from a survey conducted by the International Center of Work and Family at IESE Business School.

The main conclusions of the analysis are:

- Women have readier access to general management posts in small companies.

- The feeling of working a "double work day" is widespread among women managers, especially in large companies.

- Lack of sympathy on the part of colleagues and superiors when women give priority to their family responsibilities undermines women managers' satisfaction with their professional life.

- The main career inhibitor is corporate culture (the "glass ceiling").

- The importance that executive women ascribe to career inhibitors decreases with age and professional rank.

- The average woman manager's main support is her husband, who in most cases is also a manager.

- The principal career enablers are: motivation, training, mental strength and value system.

\footnotetext{
* Professor, Management of People in Organizations, IESE

${ }^{*}$ Associate Researcher, IESE

*** Research Assistant, IESE

${ }^{* * * *}$ Faculty of Mathematics, University of Barcelona
}

Keywords: women, top management, career, family. 


\section{CAREER INHIBITORS AND CAREER ENABLERS FOR EXECUTIVE WOMEN}

\section{Introduction}

As Izraeli and Adler (1994) point out, despite women's investment in their own education, their commitment to their management career, the shortage of international executives, and equal opportunity legislation, even today women hold no more than a small fraction of management posts. As Schein (1989) states categorically, in most countries "to think manager is to think male". What's more, 50\% of women who attain management posts do so through personal contacts with men (Davidson and Cooper, 1992), while many highly qualified women are completely excluded from the labor market, causing an extraordinary loss of talent (Hewlett, 2002). Organizations still have not developed sufficiently flexible policies to relieve women managers of the tension of having to combine family with work (Lewis, 1994).

And this situation persists despite egalitarian policies and despite research pointing to a link between gender balance in management and corporate profitability (Litz and Folker, 2002). Hewlett (2002) voices the hope that studies like this will help to create workplaces in which it is recognized that companies cannot afford to lose highly qualified women merely because they decide to start a family, and in which women are encouraged to demand more from spouses, employers and legislators, so that they are offered more generous life choices.

The purpose of this paper is to contribute to the analysis of inhibitors and enablers in the careers of executive women. The data on which we base our analysis were obtained from a survey carried out in March 2003 by the International Center of Work and Family at IESE, in which information was gathered regarding the sources of conflict between work and family and the tensions deriving from simultaneous commitment to the two. The survey results are discussed briefly in Chinchilla and León (2004).

In this paper, both the inhibitors and the enablers are analyzed along similar lines. The relative importance of the different factors is measured directly by taking the average of the survey responses, and indirectly by examining correlations with measures of success and conflict drawn from the same questionnaire.

On the inhibitor side, first we consider situations that may lead to conflict between professional and family life, forcing women to decide. From the results we derive a measure of conflict, which we use to indirectly assess career obstacles. Then, we analyze the responses regarding the inhibitors themselves, which are presented in the questionnaire as "obstacles to professional development". On the enabler side, we consider: a) the respondents' assessment of the support they receive from different sources, and b) their assessment of factors that may have contributed to their professional development. 


\section{Work-family conflict}

Work-family conflict is a central topic in studies of women's employment. In particular, studies carried out to date have shown that women holding management posts are exposed to more stress than men (Cooper and Davidsson, 1982; Greenhaus and Beutell, 1985; Jick and Mitz, 1985). According to Hewlett (2002), most women holding management posts have to choose between career or family.

In the questionnaire we used in our survey, we suggested various "feelings" of conflict that may be considered typical and that have often been described in the literature. One is the "double work day" feeling. Numerous studies point to the fact that, however many hours they work outside the home, women continue to shoulder the burden of housework, and of childcare in particular (Hochschild, 1989; Lewis and Cooper, 1987; Pleck, 1985). According to Hochschild (1989), because of the unequal distribution of housework, working women claim to have a "second work day" at home, in addition to their regular job. Hochschild believes that women are burdened with this second work day because a woman's work is considered less important than that of her husband. This argument is less convincing in the context of our study, where we are dealing with female executives, whose executive husbands are mostly of equal or inferior rank (see Table 2).

The second is the feeling that bosses and colleagues are unsympathetic when a woman has to give priority to her family duties. On this issue, Bailyn (2003) has shown that, in some cases, a woman's career development is influenced more by other people's (mostly men's) opinion of her abilities than by her actual abilities.

Thirdly, the feeling some women have of having to bring up a family on their own is one that has been discussed in the literature. Marangiu and Ekehammar (1999), for instance, state that even women at the very top of their profession retain responsibility for unpaid housework. In a study carried out by Linehan (2002), women declared that they experienced the conflict between housework and their job more intensely than their husbands. The author attributed this to the fact that women take more responsibility for organizing the family and the household.

\section{Obstacles to women's career development}

Some of the obstacles assessed in this survey have been dealt with in the literature. The first is women managers' lack of self-confidence. According to Tharenou et al. (1994), this is indirectly related to managerial promotion through training and development.

Another is lack of support from superiors. Tharenou (2001) studied access to management levels over two-year periods and found that, unlike men, the move into management is more frequent among women who receive early support from their colleagues and bosses. She also found that women who had worked closely with an executive woman and who were employed in companies with a high proportion of women managers were more likely to gain promotion than those who worked in male-dominated hierarchies.

A third obstacle, discussed by other authors, derives from family responsibilities. According to Linehan and Walsh (2000), the problem is not women's family ties in themselves, but the fact that these ties are seen as obstacles to women's availability for work, while availability is essential for promotion. Brockbank and Airey (1994) also cite dual responsibilities and family demands as obstacles, together with the absence of feminine roles and the lack of career counseling. 
In the special case of female managers, Hewlett (2002) identifies the lack of flexibility policies in companies as a career obstacle. According to her data, executive women are explicitly in favor of policies that allow them to have what has been called "the gift of time".

Lastly, the role of an adverse corporate culture as an obstacle to women executives' career development -the so-called "glass ceiling" (Davidson and Cooper, 1992)- has been studied by Traves et al. (1997) and Broadbridge (1999). According to these authors, not only do men hold most executive positions, they also perpetuate a "male" culture. Mattis (1995) recommends various proactive measures to facilitate women's advancement in management. These include training male managers to take an active role in developing women managers, adopting flexible work patterns to support work-life balance, and getting top management committed to "diversity management". Powell et al. (2002) argue that, in the eyes of authority, a good manager is still predominantly perceived as male. Antal and Izraeli (1993), after reviewing the situation in different parts of the world, declare that "probably the greatest barrier to women in the industrialized world is the persistent stereotype that associates management with being a man".

Needless to say, if we examine career inhibitors in exhaustive detail, we run the risk of drawing up a long list of factors that in practice never occur separately or in isolation, but in fact derive from a small number of common sources. We therefore need to group the inhibitors according to their origin. Thus, Mattis (1995) groups the inhibitors into attitudinal barriers, such as stereotypical perceptions; structural barriers, such as lack of contacts (network) or advice; and self-selection barriers, such as lack of confidence. Mattis does not include the barriers created by the duality of roles that are one of the main focuses of this study.

\section{Enablers of professional development}

As with the obstacles, many of the enablers described in our questionnaire as "factors in favor of professional development" have been discussed in the literature. Training, for instance, has been linked to women's advancement in management by Tharenou (1999) and Tharenou and Conroy (1994). Qualitative studies of women's career progression show that personality, or the way certain traits of women's personality are perceived, may assist or obstruct their career (Morrison et al., 1992; Seibert and Kraimer, 2001). Tomlinson et al. (1997) suggest that women managers have an advantage over men because they generally find it easier to communicate and empathize with employees.

Generally speaking, the literature is oriented mainly toward assessing the various forms of gender discrimination and contains much less discussion of enablers than of inhibitors. For the most part, published works on this subject insist again and again on the barriers that prevent women from gaining access to management positions, while paying much less attention to women's management competencies and profiles and the specificity of female management. Future research should therefore examine these matters, possibly combining quantitative studies with qualitative research. 


\section{Description of the study}

\section{Sample}

The data come from a sample of 145 women managers from all branches of industry. Eighteen percent of the respondents held general management positions, 53\% were department managers, $13 \%$ were section heads, and $4 \%$ were freelance. Seventy percent were married with children. All had university degrees and $61 \%$ had an MBA. Average length of service in their present company was more than five years. Table 1 shows the sample composition by age and professional experience.

Table 1. Description of the sample

\begin{tabular}{|c|c|c|c|c|c|c|c|}
\hline \multicolumn{8}{|c|}{ Age } \\
\hline Experience & Up to 35 & $36-40$ & $41-45$ & $46-50$ & Over 50 & Did not say & Total \\
\hline Up to 10 & 17 & & & & & 12 & 29 \\
\hline $11-15$ & 12 & 19 & & & & 10 & 41 \\
\hline $16-20$ & & 9 & 13 & 1 & & 8 & 31 \\
\hline $21-25$ & & & 6 & 5 & 1 & 7 & 19 \\
\hline More than 25 & & & 3 & 5 & 4 & 9 & 21 \\
\hline Total & 29 & 28 & 22 & 11 & 5 & 46 & 141 \\
\hline
\end{tabular}

In Table 2 we have compared the professional rank of the respondents with that of their husbands/partners. The results show a majority of couples of a similar professional rank, and more freelances among the men.

Table 2. Professional rank of the respondents and their husbands/partners

\begin{tabular}{|c|c|c|c|c|c|c|}
\hline \multirow[b]{2}{*}{$\begin{array}{l}\text { Rank of } \\
\text { respondent }\end{array}$} & \multicolumn{6}{|c|}{ Rank of husband/partner } \\
\hline & $\begin{array}{l}\text { General } \\
\text { manager }\end{array}$ & $\begin{array}{l}\text { Department } \\
\text { manager }\end{array}$ & $\begin{array}{l}\text { Section } \\
\text { head }\end{array}$ & Freelance & Other & Total \\
\hline $\begin{array}{l}\text { General } \\
\text { manager }\end{array}$ & 10 & 4 & & 4 & 7 & 25 \\
\hline $\begin{array}{l}\text { Department } \\
\text { manager }\end{array}$ & 12 & 30 & 7 & 9 & 17 & 75 \\
\hline Section head & & 7 & 3 & 2 & 6 & 18 \\
\hline Freelance & 1 & 2 & 1 & & 1 & 5 \\
\hline Other & 2 & 3 & 1 & 2 & 12 & 20 \\
\hline Total & 25 & 46 & 12 & 17 & 43 & 143 \\
\hline
\end{tabular}

Table 3 shows a clear link between company size and the respondents' professional rank. Overall, we find a very significant $(r=-0.293, p<0.001)$ negative correlation between the two. This suggests that it is easier for women to accede to general management positions in small companies. One possible explanation would be that in small organizations there are fewer 
intermediate levels, so women have fewer steps to climb on the ladder. Another explanation might be that 33\% of start-ups are created by women; another, that these are family businesses; and yet another, that small companies necessarily have a more flexible culture.

Table 3. Company size and professional rank

\begin{tabular}{lcccc}
\hline \multicolumn{1}{c}{ Company size } & $\begin{array}{c}\text { General } \\
\text { manager }\end{array}$ & $\begin{array}{c}\text { Department } \\
\text { manager }\end{array}$ & Section head & Total \\
\hline Up to 100 & 13 & 14 & & 27 \\
From 101 to 500 & 5 & 19 & 4 & 28 \\
From 501 to 1,000 & 1 & 13 & 4 & 17 \\
From 1,001 to 5,000 & 2 & 19 & 7 & 25 \\
More than 5,000 & 2 & 9 & 18 & 18 \\
\hline Total & 23 & 74 & & 115 \\
\hline
\end{tabular}

\section{Questionnaire}

A copy of the questionnaire is attached to this paper as an exhibit. In the questionnaire, the career inhibitors are divided into two thematic blocks. The first block (see results in Table 4) presented a list of situations liable to generate internal conflict. The respondents were asked to rate the severity of the conflict, in their experience, on a scale of 1 (no conflict) to 5 (very serious conflict). They were then presented with four statements illustrating a perceived conflict: a) double work day; b) unsympathetic bosses and colleagues; c) having to bring up the family on one's own; and d) husband a dead weight rather than a help. The response options went from 1 (completely disagree) to 4 (completely agree).

In the second block, nine obstacles to respondents' professional development had to be rated from 1 (not at all) to 5 (definitely). Some of these obstacles were linked to personality (e.g. lack of self-confidence), while others were related to the environment (e.g. lack of support from bosses).

On the enabler side (likewise split into two blocks), the first block dealt with different types of support the respondents received: domestic, educational, emotional and professional. They were given a list of potential supporters (husband, parents, etc.), which they had to rate from 1 (not at all) to 5 (definitely).

Next, they were asked to assess the importance of thirteen professional development enablers (training, emotional support from spouse, etc.) on a scale of 1 (not at all important) to 5 (very important).

In the last part of the questionnaire, the respondents were prompted to indicate how satisfied they were with working life, family life and life in general, on a scale of 1 (very dissatisfied) to 5 (very satisfied). 


\section{Method of analysis}

First, we compared the averages of the various items in each list to judge their relative importance. Where the differences seemed significant, we carried out a (non-parametric) statistical test. In these tests we implicitly assumed that the sample was taken at random from a population, and that the test results referred to this population. Even though this is never the case in studies in which the sample comes from the enrollment list of a business school program, the significance levels obtained are indicative and allow us to objectively compare one set of results with another.

We used the responses to the question about personal satisfaction at work, at home and in general as measures of personal success. We correlated these measures with inhibitors and enablers as a complementary analysis to the comparison of averages. The same procedure was followed with the conflict measure, which is the sum of the scores of the ten potentially conflict-generating situations.

As the normal distribution is not valid for the responses to a questionnaire like this that offers four or five response options, we used two non-parametric tests, the signed rank test and the Kruskal-Wallis test, in our comparisons of variables and groups, respectively. Similarly, except in the factorial analysis, we used Kendall's tau-b correlation (which is appropriate for ordinal variables with a small number of values) for comparisons where there was likely to be a large number of draws.

For both the obstacles and the enablers, we analyzed the correlation structure using exploratory factorial analysis based on main components and the VARIMAX rotation algorithm. The questionnaire items were grouped around three or four factors, in accordance with the coefficients.

The calculations were done with SPSS 11.0. The significance level of the statistical tests is designated by $p$. As usual, $p<0.05$ is considered significant. In the tables, to simplify the presentation, one asterisk (*) is used to indicate $0.01<p<0.05$; two $\left(^{* *}\right)$ if $0.001<p<0.01$; and three $\left({ }^{* * *}\right)$ if $p<0.001$.

\section{Results and discussion}

\section{Success measures and conflict measures}

Overall, and for these measures in particular, the respondents' responses can be described as optimistic: the success measures show high scores, and the conflict measures, low scores. This pattern is common in this type of survey, in which there are likely to be more "winners" among the respondents. So we cannot draw many conclusions from the absolute values, though we can from the comparisons and any correlations or associations we observe when we cross two variables.

In the success measures, we find higher average scores for family life (4.23) and life in general (4.13) than for working life (3.88). The differences are highly significant $(p<0.001)$. These results suggest that, although their rank and achievements might be expected to induce a degree of satisfaction with their professional life, the respondents are in fact more satisfied with their personal life. 
The correlations between these three measures are positive and significant, especially between satisfaction with family life and satisfaction with life in general $(r=0.643, p<0.001)$. We find no significant correlation between the success measures and respondent age or company size, but we do find a correlation with professional rank. Average satisfaction with working life is higher among the general managers (4.5) than among the department managers (3.9) and section heads (3.6). These differences are important on a scale of 1 to 5 , and very significant $(p<0.001)$.

The correlation between the conflict measure and satisfaction with working life is negative and significant ( $r=-0.182, p=0.037$ ), which is consistent with the choice of this measure. We find no association between the conflict measure and age, professional rank or company size.

\section{Situations that have created conflict}

Most of the potential conflict situations described in the questionnaire are found to be infrequent, the most frequent being maternity leave (65\%). Overall, the conflict in each situation is ranked low, which is consistent with the optimism reflected in the satisfaction measures discussed in the previous section. The situation considered most likely to produce conflict is that of having to turn down promotion for family reasons (2.3).

As regards the four feelings described in the questionnaire to illustrate conflicts, the average scores, in decreasing order, are: double work day feeling (3.0), feeling of having to bring up a family on one's own (2.3), unsympathetic bosses and colleagues (2.0), and deadweight husband (1.6). Except for the third, these averages have been calculated for the subset of married women only. In contrast with what was said in the previous paragraph, the scores here are high, which suggests a resistance to admit conflict when it actually presents itself.

Table 4. Feelings of conflict

\begin{tabular}{lcccc}
\hline & $\begin{array}{c}\text { Strongly } \\
\text { disagree }\end{array}$ & Disagree & Agree & $\begin{array}{c}\text { Strongly } \\
\text { agree }\end{array}$ \\
\hline Double work day & $14.1 \%$ & $14.1 \%$ & $34.3 \%$ & $37.4 \%$ \\
Unsympathetic boss and colleagues & $39.1 \%$ & $30.1 \%$ & $19.5 \%$ & $11.3 \%$ \\
Alone bringing up family & $51.5 \%$ & $22.2 \%$ & $18.2 \%$ & $8.1 \%$ \\
Husband more a burden than a help & $62.6 \%$ & $18.2 \%$ & $13.1 \%$ & $6.1 \%$ \\
\hline
\end{tabular}

These four items are significantly correlated with conflict as measured above. Also, the second item (unsympathetic bosses and colleagues) is significantly correlated ( $r=-0.141, p<0.01$ ) with working life satisfaction. We find no association with professional rank or company size, but we do find an association between company size and the double work day feeling $(r=$ $0.176, p=0.014)$. This suggests that the double work day feeling is stronger among women managers in large companies.

These findings are, on the whole, in line with what we find in the literature, especially as regards the double work day feeling and the feeling of having to bring up the family alone. Although conflict is ranked low in absolute terms, we find interesting correlations that demonstrate how important these issues are. 


\section{Obstacles to women's career development}

Overall, the score given to the obstacles is low, in accordance with the respondents' general optimism. There are, however, differences between the obstacles that speak for themselves, as can be seen in the following (ordered) list:

Corporate culture (3.27).

Other priorities (2.79).

Company has no flexibility policy (2.59).

Lack of career opportunities (2.51).

Lack of support from bosses (2.46).

Family responsibilities (2.46).

Lack of self-confidence (1.92).

Lack of dedication (1.68).

Lack of professional competencies (1.60).

Corporate culture is clearly (and significantly) more important than the rest, in keeping with the leading role attributed to it in the literature. We find no influence of company size on the respondents' assessment of obstacles, although we do find that, overall, the score decreases as age and professional rank increase. In particular, there is a significant correlation between age and the score given to lack of a flexibility policy $(r=-0.224, p=0.036)$, lack of career opportunities $(r=-0.232, p=0.025)$ and corporate culture $(r=-0.243, p=0.024)$.

We find significant differences between professional ranks as regards lack of career opportunities (averages of 2.3, 2.3 and 3.4 respectively, $p=0.006$ ) and corporate culture (averages of 2.6, 3.2 and 4.0 respectively, $p=0.005$ ). Although the importance ascribed to these obstacles is inversely proportional to respondents' professional rank (the higher the rank, the less important the obstacles are considered), all three groups agree that corporate culture is the biggest obstacle.

We also find significant differences, as was to be expected, between married and single women in the assessment of family responsibilities (averages of 2.6 and 1.6 respectively, $p=0.021$ ) and lack of flexibility policy (averages of 2.7 and 1.6 respectively, $p=0.012$ ). The average score for lack of a flexibility policy is even higher among separated women, but we must be cautious here, as the number of separated women in the sample was small.

The scores given to these obstacles are not independent, but are strongly correlated, as can be seen in Table 5. Based on these correlations, we have carried out an exploratory factorial analysis, which is summarized in Table 6 . We find a satisfactory structure for three factors. The first, to which we can unhesitatingly assign three of the items, is associated with responsibilities/priorities induced by the family. The second, with three items, is associated with the company. And the third, with two items, is associated with personal shortcomings. 
Table 5. Correlation between obstacles

\begin{tabular}{|c|c|c|c|c|c|c|c|c|}
\hline & 2 & 3 & 4 & 5 & 6 & 7 & 8 & 9 \\
\hline $\begin{array}{l}\text { 1. Lack of self- } \\
\text { confidence }\end{array}$ & $0.424^{* * *}$ & $0.296^{* * *}$ & -0.060 & 0.024 & 0.109 & 0.100 & 0.080 & 0.061 \\
\hline $\begin{array}{l}\text { 2. Lack of professional } \\
\text { competencies }\end{array}$ & & 0.161 & -0.135 & -0.082 & 0.165 & 0.116 & 0.083 & 0.074 \\
\hline $\begin{array}{l}\text { 3. Lack of support } \\
\text { from bosses }\end{array}$ & & & 0.105 & $0.209^{*}$ & $0.574^{* * *}$ & 0.115 & 0.099 & $0.450^{* * *}$ \\
\hline $\begin{array}{l}\text { 4. Family } \\
\text { responsibilities }\end{array}$ & & & & $0.470^{* * *}$ & -0.052 & $0.427^{* * *}$ & $0.439^{* * *}$ & $0.216^{*}$ \\
\hline $\begin{array}{l}\text { 5. Lack of flexibility } \\
\text { policy in the company }\end{array}$ & & & & & 0.110 & $0.185^{*}$ & $0.239^{* * *}$ & $0.438^{* * *}$ \\
\hline $\begin{array}{l}\text { 6. Lack of career } \\
\text { opportunities }\end{array}$ & & & & & & -0.051 & 0.083 & $0.486^{* * *}$ \\
\hline 7. Lack of dedication & & & & & & & $0.479^{* * *}$ & -0.013 \\
\hline 8. Other priorities & & & & & & & & $0.265^{* * *}$ \\
\hline 9. Corporate culture & & & & & & & & \\
\hline
\end{tabular}

(*) indicates $0.01<p<0.05$

$\left.{ }^{* *}\right)$ indicates $0.001<p<0.01$

$\left({ }^{* * *}\right)$ indicates $p<0.001$

Lack of flexibility policies lies halfway between the first two factors. The conclusion to be drawn from this exploratory analysis is very clear and consistent. The obstacles are concentrated in three sources: the family, the company and personal shortcomings, the latter scoring low, as is to be expected in a survey of executive women. Here our analysis differs somewhat from what we find in the literature, such as the previously cited study by Mattis (1995).

Table 6. Factorial analysis of the obstacles

\begin{tabular}{lcccc}
\hline Item & Factor 1 & Factor 2 & Factor 3 & R2 \\
\hline Family responsibilities & $\mathbf{0 . 8 3 9}$ & 0.135 & -0.187 & 0.750 \\
Lack of dedication & $\mathbf{0 . 7 8 8}$ & -0.114 & 0.258 & 0.701 \\
Other priorities & $\mathbf{0 . 7 8 4}$ & 0.065 & 0.106 & 0.631 \\
Company has no flexibility policy & $\mathbf{0 . 5 4 8}$ & 0.470 & 0.245 & 0.581 \\
\hline Lack of support from bosses & 0.086 & $\mathbf{0 . 7 6 6}$ & 0.332 & 0.705 \\
Lack of career opportunities & -0.139 & $\mathbf{0 . 8 0 4}$ & 0.151 & 0.689 \\
Corporate culture & 0.180 & $\mathbf{0 . 8 1 8}$ & 0.039 & 0.703 \\
\hline Lack of self-confidence & 0.075 & 0.135 & $\mathbf{0 . 8 0 8}$ & 0.677 \\
Lack of professional competencies & -0.019 & 0.096 & $\mathbf{0 . 8 0 6}$ & 0.658 \\
\hline
\end{tabular}


The perception of conflict is correlated mainly with items in the family component (first factor): family responsibilities $(r=0.388, p<0.001)$, lack of flexibility policies $(r=0.293, p<0.001)$, lack of dedication $(r=0.150, p=0.034)$, other priorities $(r=0.244, p<0.001)$ and corporate culture $(r=0.203, p=0.004)$.

Meanwhile, the items in the other two components are correlated with satisfaction with working life: lack of self-confidence $(r=-0.179, p=0.017)$, lack of competencies $(r=0.183$, $p=0.019)$, lack of support from bosses $(r=-0.397, p<0.001)$, lack of opportunities $(r=-0.345$, $p<0.001)$, other priorities $(r=-0.167, p=0.036)$ and corporate culture $(r=-0.294, p=0.004)$. Lastly, only one of the items, lack of self-confidence, is correlated with satisfaction with family life $(r=-0.192, p=0.011)$.

\section{Supports}

Supports are not much discussed in the literature, at least not in the detail in which they are considered in this survey. Here, we distinguish between the different areas in which woman managers may receive support and the different agents who may provide it. We analyze the correlation between the respondents' assessment of the support provided by different agents and the measures of success and conflict.

First, we find a negative and very significant correlation between the conflict measure and support from the husband $(r=-0.318, p<0.001)$. Second, for the success measures, we find a correlation between satisfaction with family life and support from the husband $(r=0.380, p$ $<0.001)$ and parents $(r=0.215, p=0.002)$, and also a correlation between satisfaction with life in general and support from the husband ( $r=0.354, p<0.001)$, parents $(r=0.215, p=0.002)$ and domestic help $(r=0.157, p=0.032)$.

Overall, these results assign an important role to the husband, more than in other parts of the questionnaire.

\section{Professional development enablers}

The enablers of professional development proposed in the questionnaire received very high scores, in contrast to the obstacles. This is in keeping with the general optimism we pointed out earlier. The highest scoring factors were motivation (4.68), training (4.40), personality/mental strength (4.40) and value system (4.33). The least highly valued were personal mentors (2.40), network of friends (2.39) and professional development policies (2.09). Despite these results, our analysis of the correlations assigns a more important role to the husband, who in the direct assessment was in an intermediate position.

We find no significant correlations with the conflict measure, but we do find correlations, in numerous cases, with satisfaction with working life: value system $(r=0.283, p<0.001)$, emotional support of spouse $(r=0.267, p=0.001)$, professional development policies $(r=$ $0.235, p=0.003)$, training $(r=0.229, p=0.003)$, motivation/mental strength $(r=0.224, p=$ 0.005), professional mentors $(r=0.205, p=0.007)$, career strategy $(r=0.168, p=0.024)$ and personal mentors $(r=0.165, p=0.038)$. Also, we find a significant correlation between satisfaction with family life and emotional support from the spouse $(r=0.386, p<0.001)$ and the spouse's opinion $(r=0.178, p=0.031)$. 
The results of the factorial analysis are not as satisfactory as for the obstacles, although when we compare the analysis of personal development with that of professional development, it is consistent. We distinguish the following components:

- An external support component, associated with professional mentors, personal mentors, luck, friends and professional development policies.

- A spouse component, associated with emotional support and the spouse's opinion.

- A personal component, associated with values, motivation and personality.

- A professional component, associated with training, time management and career strategy.

In the direct analysis, the personal component seems the most important, while in the correlations analysis, the spouse component becomes more important. In the professional component, training seems more important than the rest.

\section{Conclusions and future lines of research}

The results presented in this study suggest some points that would be worth investigating in further studies. They are summed up below.

Women have readier access to general management posts in small companies than in large ones.

The double work day feeling is very widespread among women managers, most notably in large companies.

The biggest obstacle is corporate culture (the "glass ceiling").

Overall, women managers' main support in the various spheres of life is their husbands. The husbands/partners of women managers in most cases are managers. When asked to identify the enablers of their professional development, women managers point to motivation, training, mental strength and their value system as being the most decisive factors. In their responses to other types of questions, however, they once again highlight the importance of the husband's emotional support and opinion.

Indirect analysis of the inhibitors and enablers, by correlating them with the success and conflict measures, provides an alternative perspective that confirms or qualifies the conclusions from the direct analysis. It should be pointed out, however, that women managers' assessment of the importance of the obstacles to their professional development decreases as they grow older and ascend within their profession.

Success appears to be linked to satisfaction with working life, which in turn is linked to professional rank.

Lack of sympathy on the part of bosses and colleagues when women managers give priority to their family duties is the biggest factor undermining satisfaction with working life.

The order of importance of the obstacles is as follows: adverse corporate culture, family responsibilities, and only in third place, lack of competencies. 
There is no such clear correlation among the enablers as among the obstacles, but the order of importance is as follows: spouse support, personal support, external logistical support (domestic help, schools, family members) and, lastly, professional support.

Lines of research to be pursued in the future are:

Study of dual careers.

Preparation of an annual international index of women managers.

Work-family reconciliation policies and flexible working arrangements as determining factors in women managers' careers. 


\section{References}

Antal, A.B. and D.N. Izraeli (1993), "A global comparison of women in management: Women managers in their homelands and as expatriates", in Women in Management: Trends, Issues, and Challenges in Managerial Diversity, by E.A. Fagenson (ed.), Sage, Newbury Park, pp. 52-96.

Bailyn, L. (2003), “Academic careers and gender equity. Lessons learned from MIT”, Gender, Work and Organizations, 10,2, pp. 137-152.

Broadbridge, A. (1999), “A profile of female retail managers: some insights”, The Services Industries Journal, 19,3, pp. 135-162.

Brockbank, A. and Y. Airey (1994), "Women managers in the retail industry", International Journal of Retail and Distribution, 22,4, pp. 3-13.

Chinchilla, N. and C. León (2004), "Directivas en la empresa. Criterios de decisión y valores femeninos en la empresa”, technical note DPON-14, IESE Business School.

Cooper, C. and M. Davidsson (1982), Women as Leaders, Nordstedts, Stockholm.

Davidson, M. and C. Cooper (1992), Shattering the Glass Ceiling. The Women Manager, Paul Chapman, London.

Greenhaus, J. and N.J. Beutell (1985), "Sources of conflict between work and family roles", Academy of Management Review, 10, pp. 76-88.

Hewlett, S.A. (2002), "Executive women and the myth of having it all", Harvard Business Review, April, pp. 66-73.

Hochschild, A. (1989), The Second Shift, Viking, New York.

Izraeli, D.N. and N.J. Adler (eds.), (1994), Competitive Frontiers: Women Managers in a Global Economy, Blackwell, Oxford.

Jick, T.D. and L.F. Mitz (1985), "Sex differences in work stress”, Academy of Management Review, 10, pp. 408-420.

Lewis, S. (1994), "Role tensions and dual-career couples", in Davidson, M.J. and R.J. Burke (eds.), Women in Management. Current Research Issues, pp. 230-241, Paul Chapman, London.

Lewis, S. and C.L. Cooper (1987), "Stress in dual earner couples and stage in life cycle”, Journal of Occupational Psychology, 60, pp. 289-303.

Linehan, M. (2002), "Senior international managers. Empirical evidence from Western Europe”, International Journal of Human Resources Management, 13, pp. 802-814.

Linehan, M. and J.S. Walsh (2000), "Work-family conflict and the senior female international manager”, British Journal of Management, 11, S49-S58. 
Litz, R.A. and C.A. Folker (2002), "When he and she sell seashells: exploring the relationship between management team gender balance and small firm performance", Journal of Developmental Entrepreneurship, 7,4, pp. 341-360.

Marangiu, S. and B. Ekehammar (1999), "Internal and external influences on women's and men's entry into management”, Journal of Managerial Psychology, 14,5, pp. 421-433.

Mattis, M.C. (1995), “Corporate initiatives for advancing women”, Women in Management Review, 10,7, pp. 5-14.

Morrison, A.M., R.P. White, E. Van Velsor and The Centre for Creative Leadership (1992), Breaking the Glass Ceiling, Addison Wesley, Reading.

Ouchi, W.G. (1981), Theory Z: How American Business Can Meet the Japanese Challenge, Addison-Wesley, Reading.

Pleck, J.H. (1985), Working Wives/Working Husbands, Sage, Newbury Park.

Powell, G.N., D.A. Butterfield and J.D. Parent (2002), "Gender and managerial stereotypes: Have times changed?”, Journal of Management, 28,2, pp. 177-193.

Schein, V.E. (1989), "Sex role stereotyping and requisite management characteristics, past, present and future”, Working Paper Series WC 98-26, National Centre for Management Research and Development, University of Western Ontario.

Seibert, S.E. and M.L. Kraimer (2001), “The five-factor model of personality and career success", Journal of Vocational Behavior, 58, pp. 1-21.

Tharenou, P. (2001), "Going up? Do traits and informal social processes predict advancing in management?”, Academy of Management Journal, 44,5, pp. 1005-1017.

Tharenou, P. and D. Conroy (1994), “Men and women managers' advancement”, Applied Psychology; An International Review, 43,1, pp. 5-31.

Tharenou, P., S. Latimer and D. Conroy (1994), "How do you make it to the top?", Academy of Management Journal, 37, pp. 899-931.

Tomlinson, F., A. Brockbank and J. Traves (1997), "The Feminisation of management? Issues of sameness and difference in the roles and experiences of female and male retail managers", Gender, Work and Organisations, 4,4, pp. 218-229.

Traves, J., A. Brockband and F. Tomlinson (1997), "Careers of women managers in the retail industry”, Service Industries Journal, 17,1, pp. 133-154. 